\title{
Los avatares del espacio dramático \\ en La dama duende de Calderón
}

Josefina ITURRALDE

Universidad Nacional Autónoma de México

El espacio en la obra dramática tiene, ya se sabe, un valor esencial: de cómo esté diseñado y empleado por el dramaturgo se infieren el sentido de la obra y, también, los posibles modos de representación. De este aspecto espacial se desprenden valores estéticos, morales, sociales, etcétera. Cuando el espacio no está claramente definido surgen duda y confusión. El teatro del seiscientos español en ocasiones no define de manera nítida este aspecto espacial: un ejemplo es La dama duende de Calderón. De esta famosa comedia es necesario replantear la visión y comprensión de la totalidad, pues existen otras dos versiones de la obra, desconocidas hasta hace poco. Una es de Valencia, la otra de Zaragoza y ambas publicadas el mismo año de 1636, fecha de la publicación en Madrid del texto que se ha tenido como el oficial y único autorizado por el dramaturgo.

De acuerdo con Vitse y Pacheco-Berthelot, ${ }^{1}$ las diferencias son mínimas entre las dos primeras jornadas de las tres ediciones; las variantes se encuentran en el último acto de las ediciones hasta ahora desconocidas. Estos textos difieren del madrileño no sólo en la distribución de los personajes y escenas, sino que también ponen en claro el problema espacial - piedra fuindamental en esta obra-que presenta el texto conocido. Pareciera - y digo pareciera, porque ninguno de los investigadores citados lo afirma categóricamente- que estamos ante una frecuente práctica calderoniana: la refundición. Pero lo importante aquí es que las variantes hacen transparente y lógico el uso y referencias al espacio (me refiero únicamente al espacio escénico); se ilumina lo que la edición oficiał deja confuso y sin solución

${ }^{1}$ Los datos anteriores y otros que daré se encuentran en el artículo de Marc VITSE, "Sobre los espacios en La Dama duende. El cuarto de don Manuel", Notas y estudios filologicos. UNED, Centro Asociado de Navarra, s.f., pp. 7-32. Hay un artículo que publica la tercera jornada, el de $A$. PACHECO-BERTHELOT, "La tercera jornada de La dama duende de Pedro Calderón de la Barca". Criticón 21. Toulouse-Le Mirail, 1983, pp. 49-91. 
adecuada y coherente. Los textos descubiertos gozan de una congruencia total y, sostengo, una mayor fuerza dramática, debida naturalmente a esa lógica interna del texto.

Para la mejor comprensión de lo que posteriormente señalaré, refiero brevemente la acción de este drama. Ángela, joven y hermosa viuda, vive recluida en casa de sus hermanos Juan y Luis, donde viene a hospedarse Manuel, amigo íntimo de Juan. Éste, guarda celoso de su honor, para evitar que Manuel sepa que en casa vive su hermana, hace construir una falsa alacena que tapa una puerta que existe en el cuarto del huésped y que da acceso al área donde habita Ángela. De tal manera está diseñado el espacio dramático ${ }^{2}$ que la lejanía entre los cuartos resulta considerable; la separación entre Ángela y Manuel está asegurada por obra y gracia de la alacena. Isabel, la criada de la dama, sabe cómo abrir la alacena para pasar al cuarto de Manuel. Ángela aprovecha esta situación y, para distraer un poco su recluimiento, decide hacerse presente en esa área prohibida para ella: deja ahí ropa limpia, dulces, recados inquietantes, golosinas, etcétera. Manuel no encuentra explicación racional a todo lo que le ocurre, pues ni ha visto a nadie en su habitación, ni ésta tiene, según él, otro acceso que el de la calle. Ángela y Manuel se van enamorando poco a poco, y sin que el galán conozca a la dama. Ángela arregla una entrevista clandestina en su cuarto, entrevista en la que el galán no sabe ni dónde está, ni la identidad de la mujer. Ahí llega Luis, hermano de la dama. Al esconderse el galán y el criado, Luis oye ruido $y$, obsesionado por su honor, persigue espada en mano al bulto que vio a lo lejos. Ángela decide huir, pero ya en la calle la encuentra su hermano Juan, quien mientras averigua qué pasa encierra a la dama en el cuarto de Manuel, pues cree al huésped fuera de Madrid. En esa área tan pequeña se encuentran todos los personajes: Luis que persigue a Manuel, Ángela encerrada y los criados en seguimiento de sus amos. Ángela es defendida por Manuel, quien le ofrece matrimonio. Con esta solución finaliza el drama. Pero ahora veamos las diferencias.

En La dama duende (M) conocida se nos refiere en la primera jornada que el cuarto de Manuel está realmente separado del de

2 Me baso en la concepción que da M. Issacharoff en "Space and Reference in Drama", Poetics Today, Spring 1981, vol. 2, núm. 3, pp. 211-224. Se hace aqui una diferencia entre espacio teatral, escénico y dramático, entre otras muchas e interesantes proposiciones teoricas. 
Ángela. ${ }^{3}$ La alacena —que juega el papel principal aquí-se encuentra perfectamente construida para disimular una puerta interior del área donde vivirá el huésped; esa puerta tiene acceso a un jardín interior, jardín que separa las habitaciones ${ }^{4}$ de los protagonistas:

\footnotetext{
Por cerrar y encubrir

la puerta, que se tenía, y que a este jardín salía, y poder volverla a abrir, hizo tu hermano poner portátil una alacena
}

La idea de separación considerable, de lejanía, se repite cuando Ángela se sorprende ante la proposición de su criada de pasar al cuarto del inuésped:

...¿Chómo, si se ve

de mi cuarto tan distante

el suyo?

(I.568-570 M)

Hasta aquí tanto espectador como lector se quedan con la convicción de que media un importante espacio entre ambas habitaciones. El problema se presenta cuando en la tercera jornada las alusiones al espacio parecen comprimirlo, reducirlo y situar los cuartos de los protagonistas de manera contigua y el paso de uno a otro, inmediato. Ocurre, pues, que la dificultad no tiene solución, ya que resulta contradictoria la ubicación de la alacena y los cuartos en la tercera jornada, respecto de las dos primeras ${ }^{5}$.

3 Empleo la edición que para Clásicos Castellanos preparó A. Valbuena Briones, Madrid, 1962. Para evitar confusiones, en adelante, al final del título o en las citas, pondré $\mathrm{M}=$ texto madrileño, $\mathrm{V}=$ texto valenciano.

4 Se debe entender "cuarto" como un área bastante amplia, lo que hoy se llama suite. Cfr. M. VITSE, art. cit., pp. 9-10.

5 J. E. VAREy lo explicó en su artículo "La dama duende de Calderón: símbolos y escenografía", en Calderón, Actas del Congreso Internacional sobre Calderón y el teatro español del Siglo de Oro. Madrid, 1981. CSIC, Madrid, 1983, tomo I, pp. 165-183. VITSE corrige y hace precisiones a VAREY, basándose en la edición recién descubierta, pp. 22-23 del artículo de VITSE. 
Lo que desvanece el problema es la lectura de ese tercer acto en la edición valenciana. ${ }^{6}$ En esta versión lo contradictorio desaparece: las áreas de los protagonistas se encuentran como se ubicaron desde un principio; la alacena también. Se señala que hay un "paso" - casi un pasillo- que debe recorrerse para ir de una habitación a otra7. Dice Luis, el hermano delirante, a Manuel, el galán:
si en el cuarto de esta fiera
estás, cuando siento gente,
llamo a la puerta, y te escondes
por este paso que tienes
oculto para su cuarto
y al tuyo a guardarte vienes...

(III.476-481 V)

Además, las acotaciones señalan perfectamente los movimientos que realizan los personajes; el "Ruido de puertas adentro" (V), antes del verso 350, es durante el interrogatorio que Luis está haciendo a su hermana y precisa la lejanía del ruido, lo cual se confirma en la siguiente acotación: "Toma una luz de su bufete" (V), antes del verso 367 y camina hacia clonde ha oído el ruido. Con esta acotación se mantiene la idea de lcjanía entre los cuartos de los protagonistas, pues Luis toma una vela para alumbrar el camino, el pasillo, que separa las habitaciones de Angela y Manuel. El movimiento de Luis lo lleva a encontrarse con Isabel -quien no ha podido cerrar la alacena-e interrogarla acerca de lo que sucede; junto con la criada, Luis va hacia la alacena; la acotación reza "Entran por la puerta, y salen por la alacena" (V), antes del verso 423. Con este movimiento los personajes se desplazan desde las habitaciones de Ángela y llegan así a encontrarse Luis y Manuel, con gran sorpresa de ambos, en el propio cuarto dcl huésped. Los movimientos resultan matemáticos y perfectos en ese preciso espacio. Por otra parte, esta tercera jornada presenta diferencias en la articulación entre las escenas y los perso-

6 Las citas de esta versión están tomadas de la publicada por PACHECO-BERTHELOT, art. cit., pp. 59-91.

7 VITSE habla, en apoyo a este aspecto espacial, del número de versos que hay en el texto y que corresponden al tiempo que se llevan los personajes en recorrer ese espacio que media entre los cuartos de los protagonistas; art. cit., pp. 13-14. 
najes que intervienen en ellas. Resumo las acciones en la edición valenciana.

1.- Al inicio encontramos al galán y su criado esperando ver a la dama desconocida. (En la edición madrileña está solo el galán.)

2.- Diálogo entre los enamorados. Después, mientras hablan aparte Ángela y Manuel, Cosme, el gracioso, lo hace con Beatriz y la criada; les narra entonces la historia del diablo disfrazado de mujer.

3.- Conversación entre los protagonistas; la dama se niega a revelar su identidad y se ofrece como un misterio. Beatriz, la amiga de Angela, llama "discretamente" excelencia a la protagonista para confundir aún más a Manuel.

4.- Tocan a la puerta; es Luis, quien obsesionado por su honor y celos persigue y acosa a Beatriz y a su propia hermana. Isabel lleva a esconder a Manuel y a Cosme, su criado.

5.- Luis sospecha que algo "grave" ocurre, pues oye "ruido de puertas adentro". Sigue el ruido y alcanza a ver el bulto de un hombre que huye. Ángela decide huir también.

6.- En el momento que Isabel intenta, y no puede, cerrar la alacena, llega Luis y ve que se encuentra abierta. Entra al cuarto de Manuel y sobreviene el duelo entre ambos.

7.- Juan, afuera de la casa de Beatriz, ve a una mujer (Ángela), a quien primero confunde con su dama y después reconoce como su hermana. Como resultado del diálogo con ella, decide matarla en castigo por la deshomra que le ha causado. En tanto ejecuta esta acción, determina encerrarla en el cuarto de Manuel, a quien cree fuc a de Madrid. (En la edición conocida esta escena no aparece; es Ángela la que narra lo ocurrido con su hermano.)

8. - Ángela y Manuel por fin se explican y aclaran su situación. Él decide defenderla de los hermanos.

9.- Juan y Luis determinan, en venganza, también matar a Manuel. (En cl texto oficial no ocurre esto.) 
10.- Explicación entre Manuel y Luis. El galán le da palabra de esposo a la dama. Cosme pide que lo casen con Isabel. Fin.

Como se puede observar existe una diferente distribución de escenas y personajes: la primera divergencia es la intervención de amo y criado en la visita que el galán hace a la mujer. En la versión valenciana la escena está llena de ligereza en comparación con el monólogo, un tanto rígido, en el que el enamorado narra lo acontecido tal y como lo conocemos en la edición madrileña. Ahora tenemos un diálogo fluido y lleno de gracejo por parte de Cosme, el gracioso. Las ironías del criado sirven para distender el ánimo y contrastar con la suspensión y seriedad propias del galán; además esas agudezas se dirigen a criticar toda la situación en la que está comprometido su amo. Dice Cosme al relatar el cómo y por qué fueron a dar a la casa de Ángela:

Tú valiente como un Cid, yo, como doña Jimena, venimos pues, y llegamos al citado cimenterio, adonde la silla hallamos. Mas, no sin grande misterio, negra toda la admiramos: el hombre que la traía lleno de luto venía, y los dos que la llevaban, con dos máscaras estaban, todo para pena mía. Los dos en efeto allí juntamente nos sentamos, en la silla yo, y tú en mí, que por entonces jugamos a arráncate nabo; así todo el lugar anduvimos hasta que el tino perdimos; y en fin a un portal, señor, obscuro y lleno de horror, de tal túmulo nacimos. 
Se puede apreciar la existencia aquí de una buena cantidad de datos que enfatizan el aspecto misterioso de la situación, misterio que guarda una relación con la idea de la mujer que causa todo esto como inaprensible y etérea. Además ( $y$ me parece significativo en conexión con ese halo de misterio, pero también de belleza celestial que Ángela posee) cuando ambos personajes están ante la dama, el criado exclama: "iVive Dios, que embelesado/ estoy!" (vv. 161-162 V). Esto no es frecuente, no en Cosme, quien todo lo remite a los infiernos y al poder del demonio; la escena, es decir, la que contempla Cosme, resulta de tal manera luminosa, bella y suntuosa que lo gana, a él también, la admiración de lo que está ocurriendo y presenciando.

Otra diferencia que se aprecia en el texto valenciano es el acierto del dramaturgo al incluir una conversación, en aparte, de los enamorados. No sabemos de qué hablan, pero sí podemos imaginar que ambos se encuentran presos por el amor y la atracción mutuos. Es por esto que todo lo que Manuel haga y arriesgue por Ángela se puede fundamentar en el amor que la dama le merece y no sólo como rasgo de caballerosidad al uso; no resulta pura mecánica teatral, sino afincamiento de la conducta en afectos sólidos y reales.

Aquí también es importante mencionar que cuando Luis interrumpe la reunión, Ángela dice al galán que quien llegó es su esposo, dato que intensifica aún más la posibilidad de violencia y riesgo, dada la importancia de la transgresión social y moral. (En el texto madrileño la dama dice que es su padre quien llegó.) La defensa que Manuel decide hacer de la desconocida se agudiza en sus consecuencias y causa un mayor impacto en el ánimo del galán; así que cuando Manuel reconoce a Luis, su "amigo", entrando en su cuarto, la sorpresa le resulta enorme. Otra variante en esta edición es que el único hermano que interrumpe, y acaba con la fiesta, es Luis, el hermano delirante y obsesionado por la idea del honor. Éste es quien descubre toda la tramoya que ha inventado su hermana y pelea por el honor supuestamente mancillado. Juan, el mayorazgo, se encuentra más preocupado por el amor: va en busca de su dama, Beatriz, y lo demás le causa poca preocupación. Sin embargo, lo vemos reaccionar como típico hombre celoso de su honor cuando encuentra a su hermana de noche y en la calle. Esta escena -ausente en el texto madrileñoestá llena de fuerza, tanto dramática como de contenido humano. El diálogo - casi monólogos alternos- entre los hermanos, en una situación límite, preña la escena de una fuerza total; cosa que no ocurre en el texto madrileño. En este último todo lo ocurrido lo relata Ángela con gran emoción; pero siempre lo representado, lo per- 
cibido directamente, cobra mayor fuerza e impacto en el espectador y todo esto me parece innegable en la escena que comento. En esta escena del texto valenciano (llena de admiraciones, apartes, exclamaciones, puntos suspensivos, paréntesis) apreciamos a una Ángela minimizada, disminuida como mujer y sujeta a la autoridad masculina (su juego ha desaparecido). Ella acata, de manera incondicional, las decisiones del representante de la autoridad, a quien llama "Señor, padre y hermano" (v. $723 \mathrm{~V}$ ). La actitud es de tal rendimiento frente al guardián del honor familiar que le dice convencida:

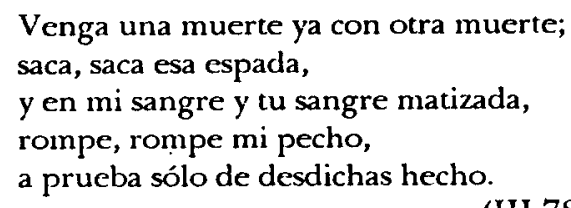

(III.729-733 V)

Lo que también se aprecia en el texto valenciano es que final y desenlace se encuentran muy próximos, lo cual sostiene la tensión del espectador casi hasta el último verso de la obra. Y si recordamos que Lope aconsejaba en su Arte nuevo que el público no pudiera adivinar en qué pararía aquello que observaba, el caso de La dama duende resulta logrado espléndidamente. Aunado a esto que comento, en esta tercera jornada, se aprecian algunas de las características que Sloman 8 determina en el arte calderoniano; es decir, "el cuidadoso razonamiento estructural de las entradas y salidas" de los personajes, como también una maestría en el "manejo del tiempo que transcurre en el desarrollo de la acción"; aspecto éste que también señala Vitse en su artículo ya citado (pp. 29-30).

De acuerdo con todo lo anterior, encuentro en esta variante textual una excelencia formal de la comedia en su totalidad: las contradicciones espaciales desaparecidas, la rapidez con que se llega al clímax de las acciones, su desenlace y final unidos crean una tensión dramática más acentuada y efectiva. Las decisiones y acciones de los

8 A.E. Sloman, The Dramatic Craflsmanship of Calderon. Oxford, The Dolphin Book, 1969 , p. 12. 
personajes llevan a la comedia por los linderos de la tragedia; sólo porque la voluntad del dramaturgo está con la protagonista, ésta se salva de ser víctima de la ley del honor, de ser una más de esas ajusticiadas de las tragedias de honor. $Y$ es que el amor juega aquí un papel importante: el sentimiento es real y une a los protagonistas; dama y galán se han conquistado mutuamente a lo largo de los días y su deseo de proximidad y acercamiento les es necesario en razón del sentimiento que los une. Así que Calderón salva a la mujer, no porque no sea un tanto culpable en todo lo que ha llevado a cabo, sino porque ella, en gran medida, tiene razón en desear vivir con libertad. Critica el dramaturgo la necesidad de ocultamiento de unas relaciones que no pueden ser públicas, a causa de la deshonra ${ }^{9}$ de Ángela por estar arreglando las malas cuentas que dejó su difunto marido y por su propia viudez que la obliga a vivir encerrada. En el texto valenciano se intensifica, pues, la significación de la obra en su sentido social; los aspectos formales y técnicos resultan perfectos, sin abrigar duda o confusión en el empleo de algo sustancial al teatro, quiero decir el espacio... y todo lo que de él se deriva.

${ }^{9}$ La idea la tomo del artículo de A. A. PARKer, "Los amores y noviazgos clandestinos en el mundo dramático-social de Calderón", en Hacia Calderón, 2o. Coloquio Anglogermano. Hamburgo, 1970. Berlín, Nueva York, Walter de Gruzter, 1973, pp. 79-87. 